Original Article

\title{
THERMAL DEGRADATION KINETICS OF KAEMPFEROL AND QUERCETIN IN THE PRE- FORMULATED OF THE STANDARDIZED EXTRACTS OF POINCIANELLA PYRAMIDALIS (TUL.) L. P. QUEIROZ OBTAINED BY SPRAY DRYER
}

\author{
AGNA HÉLIA DE OLIVEIRA ${ }^{a^{*}}$, RENATA DA SILVA LEITE ${ }^{b}$, FABRÍCIO HAVY DANTAS ${ }^{b}$, VALMIR GOMES DE SOUZAa, \\ JOSÉ VENÂNCIO CHAVES JÚNIORa, FÁBIO SANTOS DE SOUZAa, RUI OLIVEIRA MACEDOa
}

aDepartamento de Ciências Farmacêuticas, Universidade Federal da Paraíba, João Pessoa, PB, Brazil, bDepartamento de Ciências Farmacêuticas, Universidade Federal de Pernambuco, Recife, Brazil Email: agnahelia@yahoo.com.br

Received: 05 Jan 2017 Revised and Accepted: 29 Apr 2017

\section{ABSTRACT}

Objective: The aim of this work was to evaluate the stability and determine the kinetic parameters of degradation of biomarkers kaempferol and quercetin, present in the pre-formulated of the extract of Poincianella pyramidalis obtained by a spray dryer.

Methods: A $2^{3}$ experimental design coupled with RSM was applied to evaluate and optimize the effects of processing parameters on the content of chemical markers in dry extracts by a spray dryer. Stability testing was performed to verify the influence of temperature on the degradation of kaempferol and quercetin present in the pre-formulated. The markers contents were determined by HPLC.

Results: Surface response analysis showed the influence of the independent variables on the responses of the concentration kaempferol and quercentin biomarkers on the process. The variables of the inlet air temperature, flow feed rate and the adjuvant ratio presented negative responses with significant difference $(\mathrm{p}<0.05)$. According to the data obtained in the stability of the pre-formulated studied zero and second orders kinetics models the for degradation of the kaempferol and only second order kinetic model for the quercetin. It was also evaluated reducing the concentration of both biomarkers studied throughout the study.

Conclusion: In the present study, it was observed that all independent variables of the drying process by spray dryer showed the greatest influence on the concentration of the studied markers. Two markers had a different thermal behavior compared to the different excipients studied and there was degradation of both the quercentin biomarker and kaempferol during the study period.

Keywords: Poincianella pyramidalis, Spray dryer, Excipients, Stability

(C) 2017 The Authors. Published by Innovare Academic Sciences Pvt Ltd. This is an open access article under the CC BY license (http://creativecommons.org/licenses/by/4.0/) DOI: http://dx.doi.org/10.22159/ijpps.2017v9i6.16935

\section{INTRODUCTION}

Poincianella pyramidalis (Tul.) L. P. Queiroz is an arboreal species belonging to the family Fabaceae, endemic to the northeastern region of Brazil, mainly in the caatinga biome, popularly known as "catingueira", "pau de porco", "catinga de porco", "pau de rato", "mussilaba" e "catingueira-das-folhas-largas"[1]. It is used in tradicional medicine for the treatment of gastritis, colic, diarrhea, asthma, bronchitis, diabetes, as an expectorant, cicatrizant, antiinflammatory and diuretic [2-5].

Due to the great diversity of traditional uses and the importance of this species to the caatinga biome, several researchers from different areas of knowledge have shown interest in the study of this species. Phytochemical investigations have demonstrated the presence of secondary metabolites, such as flavonoids, diterpenes, tannins and lignans [6-10]. Several biological activities have already been tested with this species, among which we can highlight the antimicrobial activity against Staphylocus aureus, Escherichia coli, Enterococcus faecalis, Klebsiella pneumoniae, Salmonella spp., S. Aureus e Pseudomonas aeruginosa, antioxidant, gastro protective, anti-inflammatory, antinociceptive and anthelmintic activity, which corroborates many of its traditional uses. Due to these proven pharmacological properties, this species has a great potential for the development of a herbal medicine with ample spectrum of action [11-16].

Obtaining standardized plant extracts has been one of the major challenges for the development of herbal medicines, especially in Brazil, and the herbal industry has sought alternatives to solve this problem, one of which would be the production of standardized dried extracts of medicinal plants aiming establishment of quality control parameters for the vegetable raw material [17-19].
Spray drying is one of the most commonly used drying techniques in the preparation of dried vegetable extracts, providing products with suitable technological properties in a short time of drying and with a high production capacity [20-21], however this process can also be affected significantly by parameters such as air inlet temperature, feed flow rate and concentration of carrier agent in the mixture [2223]. Response surface methodology (RSM) is a widely used tool to evaluate the effects of the various factors in the process and to define the best conditions for the desired responses [23-25].

Ensuring the stability of the plant extracts is essential to preserve the quality, safety and efficacy of the final product, accelerated stability studies are considered predictive tools with emphasis on qualitative results, but of great use for the design of new formulations and products. Since from the first signs of instability of a drug or marker, it is possible to assist in the identification of potential problems of development, as well as to articulate strategies of stabilization and to suggest ways to optimize the manufacturing processes [26].

The aim of this work was to determine the thermal degradation kinetics of the biomarkers kaempferol and quercetin in the preformulated dry extract of Poincianella pyramidalis.

\section{MATERIALS AND METHODS}

Herbal material and chemicals

Leaves of Poincianella pyramidalis, were collected in the city of Serra Branca, State of Paraíba, Brazil. (7³0'51.1”S 36²41'91.5”0). The voucher specimen are deposited at the herbarium Lauro Pires Xavier of the Federal University of Paraíba, Brazil, under number NC36. The herbal material was dried in an oven with circulating air 
(Tecnal $®$, Model TE-394-4), at $40^{\circ} \mathrm{C}$. After drying the material was reduced in an industrial mill to obtain the powder.

In the present study, the ethanol absolute (Toscano®, Brazil), chloroform and hexane, analytical grade (Vetec ${ }^{\circledR}$, Brazil), methanol grade HPLC (Tedia Brazil, Rio de Janeiro, RJ, Brazil) Anhydrous phosphoric acid $\left(\right.$ Merck $^{\circledR}$, Germany) were used. The water was purified using aMilli-Q system (Millipore, Massachusetts, USA).

The analytical standards kaempferol (purity: 98\%) and quercetin (purity: 97\%) were obtained from Sigma-Aldrish ${ }^{\circledR}$. The pharmaceutical excipients: microcrystalline cellulose 102 (MC) starch (ST), lactose (LC), maltodextrin (MD) and carrier agent colloidal silicon dioxide 200 (CSD) were all purchased from Brazilian suppliers.

\section{Preparation of hydro alcoholic extract}

The leaf powder was subjected to maceration with ethanol-water $50: 50(\mathrm{v} / \mathrm{v})$ at plant: solvent ratio of 20:100 (w/v), for a period of $120 \mathrm{~h}$ at room temperature. The extractive conditions were previously studied and optimized by our research group, in order to obtain the best yield of the biomarkers kaempferol and quercetin.

\section{Spray drying}

The spray-drying process was carried out in a mini Spray-Dryer (LabPlant ${ }^{\circledR}$, model SD-05, Huddersfield, UK), with a concurrent flow regime, equipped with a peristaltic pump connected to a two-fluid atomizer, with a internal orifice of $1.2 \mathrm{~mm}$, which operated with an air flow rate, $\mathrm{W}_{\mathrm{g}}=40 \mathrm{~L} / \mathrm{min}$ and constant pressure of 2.0 bar. The operating parameters of the process were following: drying air inlet temperature $\left(160,170\right.$ and $\left.180{ }^{\circ} \mathrm{C}\right)$, air flow feed rate of the drying composition fed to the spray drying (4, 6 and $8 \mathrm{ml} / \mathrm{min}$ ) and proportion of colloidal silicon dioxide in the drying composition (10, 15 and $20 \%$ ).

\section{Experimental design}

A $2^{3+1}$ factorial experimental design coupled with surface response methodology (RSM) was applied to evaluate and optimize the effects of processing parameters on the content of chemical markers kaempferol $\left(\mathrm{Y}_{1}\right)$ and quercetin $\left(\mathrm{Y}_{2}\right)$. Therefore were investigated the individual and interactive effects of the following independent variables: drying air inlet temperature $\left(\mathrm{X}_{1}\right)$, air flow feed rate of the drying composition fed to the spray drying $\left(\mathrm{X}_{2}\right)$ and proportion of colloidal silicon dioxide in the drying composition $\left(\mathrm{X}_{3}\right)$. Table 1 shows the coded and encoded values in the design experimental.

\section{Statistical analysis}

The experimental data were analyzed with the aid of the Statistica 13.1 software program (Dell Inc., Tulsa, USA). The results were expressed as mean \pm SD and coefficient of variation. The means were compared using ANOVA/SRM. Differences were considered statistically significant at $\mathrm{p}<0.05$ and larger values were not considered. A total of 9 experiments runs were performed, including the medium point, with nine, replicates for each of them.

The parameters of the kinetic models and the arrhenius equation were obtained by linear regression. The order of reaction was chosen by comparing the correlation coefficients.

Table 1: Factors coded and non-coded and their levels in fractional factorial design $\left(2^{3+1}\right)$

\begin{tabular}{|c|c|c|c|c|c|c|}
\hline Runs & $\mathrm{X}_{1}$ (IT) & $\mathrm{X}_{2}$ (FFR) & $\mathrm{X}_{3}$ (CSD) & IT $\left({ }^{\circ} \mathrm{C}\right)$ & FFR (ml/min) & CSD (\%) \\
\hline 1 & -1 & -1 & -1 & 160 & 4 & 10 \\
\hline 2 & -1 & +1 & -1 & 160 & 4 & 10 \\
\hline 3 & -1 & -1 & +1 & 180 & 8 & 20 \\
\hline 4 & -1 & +1 & +1 & 180 & 8 & 20 \\
\hline 5 & +1 & -1 & -1 & 180 & 4 & 10 \\
\hline 6 & +1 & +1 & -1 & 160 & 4 & 10 \\
\hline 7 & +1 & -1 & +1 & 180 & 8 & 20 \\
\hline 8 & +1 & +1 & +1 & 180 & 8 & 20 \\
\hline 9 & 0 & 0 & 0 & 170 & 6 & 15 \\
\hline
\end{tabular}

IT: air inlet temperature, FFR: air flow feed rate of the drying composition, CSD: the proportion of colloidal silicon dioxide.

\section{Pre-formulated}

Pre-formulated were prepared from fisical mixtures of the nebulized extract (NE) and the following pharmaceutical excipients: starch (ST), microcrystalline cellulose 102 (MC), maltodextrin (MD) and lactose (LC) in the proportion of 1:1. The powder of the blends was calibrated in 48 mesh sieves and mixed mechanically for $15 \mathrm{~min}$. The tests were performed in 9 replicates.

\section{Quantification of chemicals markes quercetin and kaempferol}

The quercetin and kaempferol contents were determined using Highperformance liquid chromatography (Shymadzu, Tokyo, Japan), equipped with LC-20 AT multi-solvent supply system, DGU-20A5 degassing system, SIL-20A auto-sampler, CTO-20A column furnace and detection by electron spectrometry in the ultraviolet-visible region with SPD-M20A UV-VIS diode array, at $370 \mathrm{~nm}$. The mobile phase used was a mixture of methanol: phosphoric acid 1\% (47\%: $53 \%$ ) in the isocratic system, $\mathrm{pH} 3.1$ and flow of $1.2 \mathrm{ml} / \mathrm{min}$. The stationary phase was a C-18 Gemini $5 \mu, 150 \times 4.6 \mathrm{~mm} \times 0.5 \mu \mathrm{m}$ (Phenomenex) column.

Samples were prepared according to the previously described methodology [27]. A standard solution $4 \mu \mathrm{g} / \mathrm{ml}$ of de kampferol and quercetin was prepared with methanol: water (70:30). All sample and standard solutions were filtered through $0.45 \mu \mathrm{m}$ PTFE membrane (Millipore, Massachusetts, USA).
The method was previously validated by our working group. Parameters of validation, such as selectivity, linearity, detection and quantification limits and precision were established according to ICH Q2B [28]. The calibration curve was found to be linear over a kaempferol and quercetin concentration range of 0.4 to $7.6 \mu \mathrm{g} / \mathrm{ml}$ presenting a coefficient of the linear regression analysis was within $>0.999$. The Limit of Detection (LOD) for kaempferol and quercetin were 0.07 and $0.18 \mu \mathrm{g} / \mathrm{ml}$, respectively. The Limit of Quantification (LOQ) for kaempferol and quercetin were 0.22 and $0.56 \mu \mathrm{g} / \mathrm{ml}$, respectively. The method proved to be robust for small, deliberate changes in temperature, flow and $\mathrm{pH}$ of the mobile phase with RSD \% <3.0\%. The Relative Standard Deviation (\%) values for markers (intra-and inter-day precision studies) were $<5.0 \%$ and the accuracy was $>95 \%$.

\section{Stability testing}

Stability testing was performed to verify the influence of temperature on the degradation of bioactive compounds, present in the pre-formulated. Kaempferol and quercetin were used as chemicals markers. The tests were carried in a B. O. D (Tecnal TE371 ) incubator with temperature control, for a period of $180 \mathrm{~d}$ under a temperature $40 \pm 2{ }^{\circ} \mathrm{C}$. Approximately $3 \mathrm{~g}$ of samples was placed in hermetic PVC-aluminum sachets. The amount of the kaempferol and quercetin markers were periodically analyzed (90 and 180 d) by HPLC and compared to that present at zero time. The assays were carried out in 9 replicates. 
For the determination of kinetic parameters of reaction order (n) and decomposition rate constant $(\mathrm{k})$ the Arrhenius equation was used:

$$
\kappa=A e^{-\frac{E_{a}}{R T}}(1)
$$

Where:

$\kappa$ is the chemical reaction rate, Ae is the pre-exponential factor, $E_{a}$ is the activation energy $(\mathrm{J} / \mathrm{mol}), \mathrm{R}$ is the ideal gas constant $(8.314 \mathrm{~J} / \mathrm{mol} . \mathrm{K})$ and $\mathrm{T}$ is the absolute temperature.

Experimental data of kaempferol and quercetin degradation were fitted by zero and second-order kinetic models, given by Eqs. (2) and (3), respectively [29].

The zero-order reaction rate was obtained directly from the mass data and plotted against time according to the following equation:

$$
\mathrm{C}=\mathrm{C}_{0}-\kappa \mathrm{t}(2)
$$

Where:

C is concentration at time $t, C_{0}$ is initial marker concentration, and $\kappa^{\prime}$ is the reaction constant zero-order.

The second-order reaction, the inverse of the concentration is plotted versus at time $t$, according to the following equation:

$$
\frac{1}{[\mathrm{C}]}=\frac{1}{\left[\mathrm{C}_{0}\right]}+\kappa^{\prime \prime} \mathrm{t}(3)
$$

Where:

$\mathrm{C}$ is concentration at time $\mathrm{t}, \mathrm{C}_{0}$ is initial marker concentration, and $\mathrm{\kappa}^{\prime \prime}$ is the reaction constant second-order.

\section{RESULTS AND DISCUSSION}

Effect of drying operating conditions on the concentration of monitored chemical markers

According to the data obtained, it was verified that the operational conditions of drying by dry spray influenced the concentration of the two chemical markers studied, kaempferol and quercetin, a fact explained by the physicochemical characteristics. Table 2 shows the total number of experiments that were carried out and the concentrations of the chemical markers obtained in each of them, where it was observed that the highest concentration obtained for the kaempferol and quercetin markers, respectively, was in experiment 7 $(0.87 \mathrm{mg} / \mathrm{g} \pm 0.02$ and $1.55 \mathrm{mg} / \mathrm{g} \pm 0.04)$, corroborating with the response surface graphs (fig. 1), which show that the concentrations of the markers increase with minimum levels of the three factors studied, whereas the lowest concentrations recorded were obtained in experiments 1 and 5 for kaempferol and 1 and 8 for quercetin.

Table 2: Experimental design for spray drying runs, independent variables, with their corresponding response values

\begin{tabular}{llllll}
\hline Run & \multicolumn{2}{l}{ Independent variables } & & Response 1 & Response 2 \\
\cline { 2 - 6 } & IT $\left({ }^{\circ} \mathbf{C}\right)$ & FFR (ml/min) & SDC $(\%)$ & Kaempferol content $(\mathbf{m g} / \mathbf{g})^{*}$ & Quercetin content (mg/g)* \\
\hline 1 & 180 & 4 & 20 & $0.68 \pm 0.02$ & $1.28 \pm 0.05$ \\
2 & 180 & 8 & 20 & $0.70 \pm 0.02$ & $1.34 \pm 0.03$ \\
3 & 180 & 4 & 10 & $0.75 \pm 0.03$ & $1.39 \pm 0.05$ \\
4 & 160 & 8 & 10 & $0.79 \pm 0.03$ & $1.44 \pm 0.06$ \\
5 & 160 & 8 & 20 & $0.68 \pm 0.02$ & $1.31 \pm 0.04$ \\
6 & 180 & 8 & 10 & $0.74 \pm 0.03$ & $1.35 \pm 0.06$ \\
7 & 160 & 4 & 10 & $0.87 \pm 0.02$ & $1.55 \pm 0.04$ \\
8 & 160 & 4 & 20 & $0.75 \pm 0.01$ & $1.28 \pm 0.05$ \\
9 & 170 & 6 & 15 & $0.79 \pm 0.03$ & $1.45 \pm 0.06$ \\
\hline
\end{tabular}

*Values represent the mean \pm Standard deviation $(n=9)$, IT: air inlet temperature, FFR: air flow feed rate of the drying composition, CSD: proportion of colloidal silicon dioxide

Table 3 and fig. 1 shows the effects between the selected independent variables (IT, FFR and CSD) on the development and optimization of the drying process of the P. pyramidalis extract, using as a response the concentration of the markers kaempferol and quercetin.

Statistical analysis of the experimental data (table 3) showed that both the quercetin and kaempferol concentrations were significantly influenced by all the independent variables when the primary effects were evaluated, being the air inlet temperature $\left(\mathrm{X}_{1}\right)$ and the carrier ratio $\left(\mathrm{X}_{2}\right)$ were the most important variables in the analysis of the responses. The secondary effects were too observed for both responses in the following interactions: IT $\left(\mathrm{X}_{1}\right)$ x FFR $\left(\mathrm{X}_{2}\right)$ and IT $\left(\mathrm{X}_{1}\right)$ $x \operatorname{CSD}\left(X_{3}\right)$, with significance level $p<0.05$. The tertiary interaction between IT x FFR x CSD factors exerted significant influence only on quercetin label. This shows that the concentrations obtained are also influenced by the nature of chemical markers.
Surface response analysis was used to evaluate the individual variables and interactive effects on drying process investigated in this study. A 3D response surface plot (fig. 1) showed the influence of the individual and secondary effects studied on the responses. The negatives effects of the inlet air temperature $\left(\mathrm{X}_{1}\right)$ and the adjuvant ratio (\%) on the responses showed a significant difference $(p<0.05)$. This can be explained by the fact that at a higher temperature has a direct impact in the degradation of chemical compounds of the extract. Similar results were described by Thirugnanasambandham and Siva Kumar in the study of the influence of process conditions on the physicochemical properties of pomegranate juice in spray drying process [30] and by Patil, Chauhan and Singh, who performed a work for optimization of the spray-drying process for developing guava powder using response surface methodology [24]

Table 3: Summary of significant factor effects according to ANOVA

\begin{tabular}{lll}
\hline Independent variable & p-value & \\
\cline { 2 - 3 } & Kaempferol content & Quercetin content \\
\hline IT $\left(\mathrm{X}_{1}\right)$ & $0.000000^{*}$ & $0.000000^{*}$ \\
FFR $\left(\mathrm{X}_{2}\right)$ & $0.000972^{*}$ & $0.000444^{*}$ \\
CSD $\left(\mathrm{X}_{3}\right)$ & $0.000000^{*}$ & $0.000000^{*}$ \\
IT $\left(\mathrm{X}_{1}\right)$ x FFR $\left(\mathrm{X}_{2}\right)$ & $0.001395^{*}$ & $0.000665^{*}$ \\
IT $\left(\mathrm{X}_{1}\right)$ x CSD\% $\left(\mathrm{X}_{3}\right)$ & $0.000624^{*}$ & $0.015135^{*}$ \\
FFR $\left(\mathrm{X}_{2}\right)$ x CSD $\%\left(\mathrm{X}_{3}\right)$ & 0.342668 & 0.129123 \\
IT $\left(\mathrm{X}_{1}\right)$ x FFR $\left(\mathrm{X}_{2}\right)$ x CSD\% $\left(\mathrm{X}_{3}\right)$ & 0.280519 & $0.030913^{*}$ \\
\hline
\end{tabular}

" $\mathrm{p}<0.05$ significant effect 


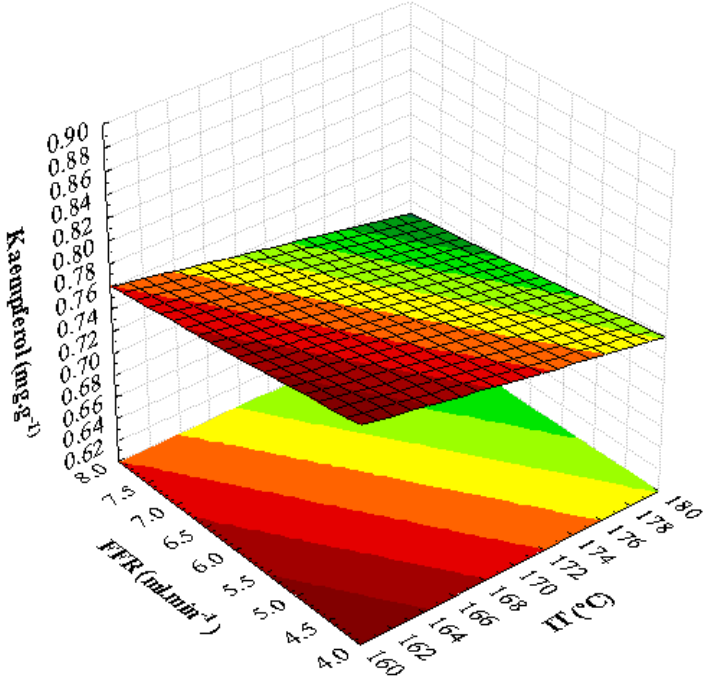

(a)

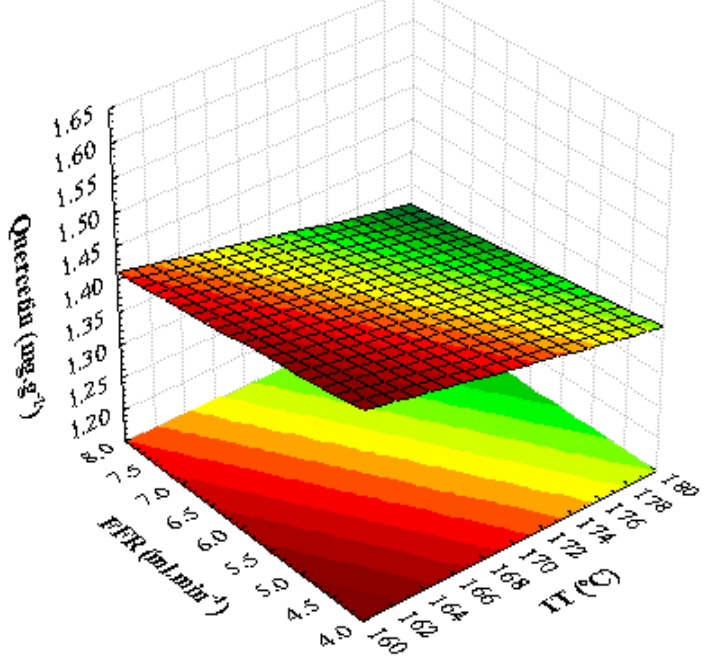

(c)

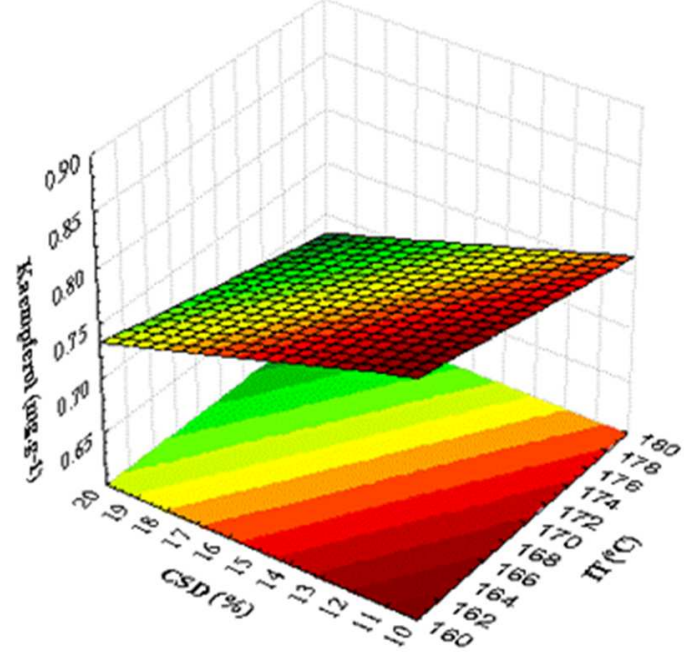

(b)

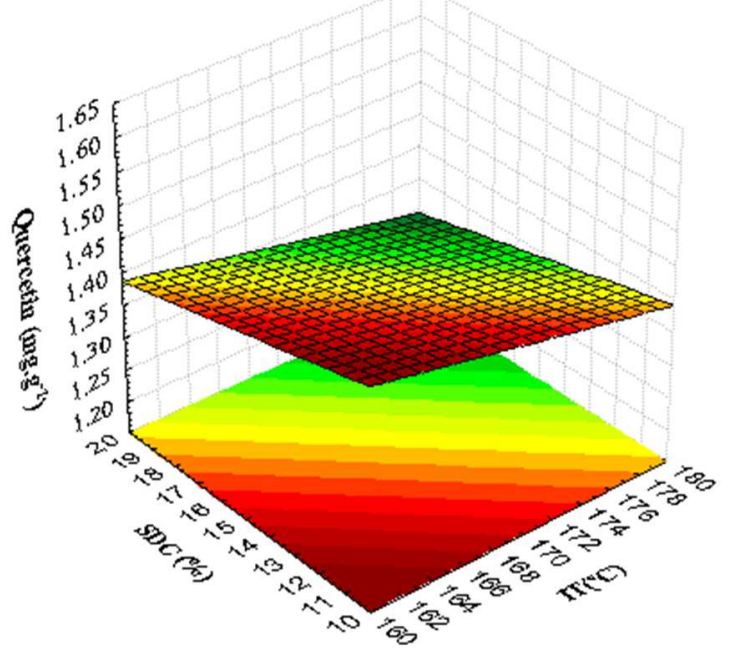

(d)

Fig. 1: Response surface showing the effects of the process parameters, air inlet temperature, air flow rate of the drying composition, proportion of colloidal silicon dioxide in kaempferol and quercetin contents

\section{Stability testing}

The Arrhenius method was used to determine the decomposition kinetic parameters following: reaction order (n), decomposed fraction $\alpha_{0.9}$ and rate constant $(k)$.

Table 4 shows the kinetic parameters and regression coefficients $\left(\mathrm{R}^{2}\right)$ that defined two kinetic models for the biomarker kaempferol, zero order kinetic model for the preformulated NE: ST and NE: LAC and second order model kinetic for following binaries mixtures: NE: MC 102, this shows that the excipients directly influenced in the kaempferol degradation kinetics.

The values of the degradation constants of kaempferol marker are in accordance with the laws of classical kinetics, which showed an exponential progression in relation to the temperature (fig. 2). According to the results obtained in the kinetic study, the times corresponding to the fraction decomposed $\alpha_{0.9}$ of the concentrations of the marker studied presented values in the range 50.90 to 64.68 $\mathrm{d}$, demonstrating a variation in the stability of the pre-formulated, with the following order of stability: NE: ST $<$ NE: MC $102<\mathrm{NE}$ : $\mathrm{MD}<\mathrm{NE}$ : LAC.

The pre-formulations showed a second order kinetic degradation for the marker quercetin since the rate constants presented an exponential behavior based on correlation coefficients ( $\mathrm{R}^{2}$ ) (fig. 3). The quercetin biomarker, a second-order kinetic model was defined for all preformulated, thus suggesting that the quercetin marker has a similar thermal behavior for the four excipients studied. The degradation constants showed that the kinetic decomposition profiles of ESN: ST, ESN: MMC 102 and ESN: MD showed differences in the times corresponding to the decomposed fraction $\alpha_{0.9}$ with variations between 67.31 to $107,3 \mathrm{~d}$ (table 4).

The mechanism of flavonoids thermal degradation was explained by Scibisz, who suggested that under the influence of heat, glycosidic bonds in dye molecules undergo hydrolysis leading to unstable aglycones [31]. Also, it has been explained that polyphenols stability, eg. Anthocyanin, a decreases with increasing number of free hydroxyl groups in the B-ring increase [32]. The results obtained in this study are in agreement with others studies reported and indicate that the spouted bed and spray dryer extracts of medicinal plants, eg. Passiflora alata tended to be hygroscopic and have a short shelf life. The dried extracts of a medicinal plants are a very complex mixture of chemical substances and each one likely degrade at a different rate. However, the use of packaging with low water vapor permeability, for example, laminated aluminium film, and lower storage temperatures would significantly increase the product stability [33]. 
Table 4: Kinetics parameters of the chemical markers on the preformulated on conditions storage $40^{\circ} \mathrm{C}$ during $180 \mathrm{~d}$

\begin{tabular}{|c|c|c|c|c|c|c|c|c|}
\hline \multirow[t]{2}{*}{ Samples } & \multicolumn{4}{|c|}{ Kaempferol } & \multicolumn{4}{|c|}{ Quercetin } \\
\hline & $\begin{array}{l}k \\
\left(d^{-1}\right)\end{array}$ & $\mathbf{R}^{2}$ & $\begin{array}{l}\text { Decomposed fraction } \alpha_{0,9} \\
\text { (d) }\end{array}$ & $\begin{array}{l}\text { Kinetic } \\
\text { model }\end{array}$ & $\begin{array}{l}k \\
\left(d^{1}\right)\end{array}$ & $\mathbf{R}^{2}$ & $\begin{array}{l}\text { Decomposed fraction } \alpha_{0,9} \\
\text { (d) }\end{array}$ & $\begin{array}{l}\text { Kinetic } \\
\text { model }\end{array}$ \\
\hline ESN: ST & $\begin{array}{l}-2.85 \mathrm{E}- \\
02\end{array}$ & 0.999 & 64,42 & Zero-Order & $\begin{array}{l}1.00 \mathrm{E}- \\
03\end{array}$ & 0.964 & 67,31 & $\begin{array}{l}\text { Second- } \\
\text { Order }\end{array}$ \\
\hline $\begin{array}{l}\text { ESN: MMC } \\
102\end{array}$ & $\begin{array}{l}7.00 \mathrm{E}- \\
05\end{array}$ & 0.993 & 63,21 & $\begin{array}{l}\text { Second- } \\
\text { Order }\end{array}$ & $\begin{array}{l}1.00 \mathrm{E}- \\
03\end{array}$ & 0.950 & 70,52 & $\begin{array}{l}\text { Second- } \\
\text { Order }\end{array}$ \\
\hline ESN: MD & $\begin{array}{l}5.00 \mathrm{E}- \\
05\end{array}$ & 0.999 & 50,90 & $\begin{array}{l}\text { Second- } \\
\text { Order }\end{array}$ & $\begin{array}{l}1.00 \mathrm{E}- \\
03\end{array}$ & 0.898 & 107,3 & $\begin{array}{l}\text { Second- } \\
\text { Order }\end{array}$ \\
\hline ESN: LAC & $\begin{array}{l}-5.74 \mathrm{E}- \\
02\end{array}$ & 0.970 & 64,68 & Zero-Order & $\begin{array}{l}2.00 \mathrm{E}- \\
03\end{array}$ & 0.988 & 248,5 & $\begin{array}{l}\text { Second- } \\
\text { Order }\end{array}$ \\
\hline
\end{tabular}

(a)

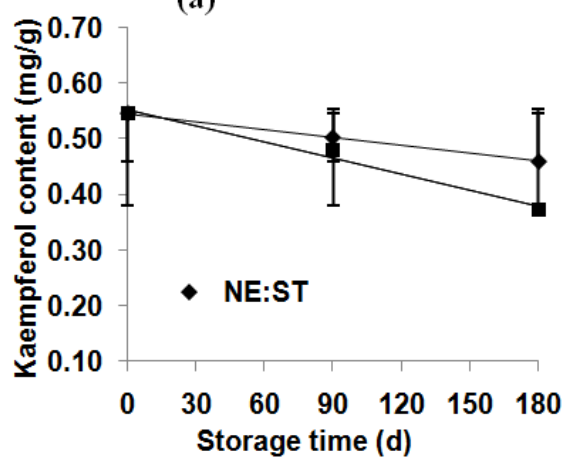

(b)

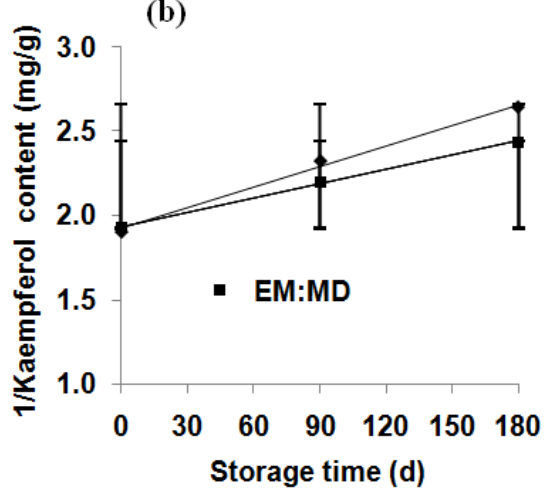

Fig. 2: Degradation kinetic kaempferol of the preformulateds during times storage: (a) nebulized: starch, nebulized: lactose zero-order model (b) nebulized: maltodextrin, nebulized: microcrystalline cellulose, second-order model

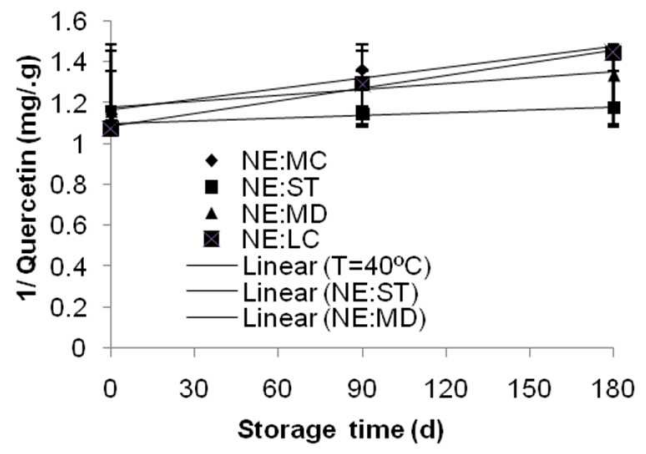

Fig. 3: Degradation kinetic quercetin of the preformulateds during times storage

\section{CONCLUSION}

In the present study, the effects of the spray dryer process conditions, such as IT, FFR and CSD, on the following responses were evaluated: the levels of the phytochemical markers quercetin and canferol in obtaining the dry extract of Poincianella pyramidalis and the results showed that all the responses studied were significantly affected by the process conditions, and the IT and CSD were the independent variables that showed the greatest influence on the concentration of the studied markers. The analysis of the surface methodology allowed to define the optimum conditions of the process, to obtain the maximum concentrations of the monitored markers.

The stability study of the preformulateds showed a king different degradation kinetics for the kaempferol phytochemical marker, with zero order and second order kinetics, while the quercetin marker showed second order degradation kinetics, thus demonstrating that the two markers have a different thermal behavior compared to the different excipients studied.

\section{ACKNOWLEDGEMENT}

The authors acknowledge the fellowships received from ConselhoNacional de Pesquisa (CNPq)

\section{AUTHOR CONTRIBUTION}

Oliveira $\mathrm{AH}$, performed analysis of all samples, interpreted data, wrote the manuscript and acted as the corresponding author; Leite, RS, Souza VG and Júnior, JVC and Dantas, FH, helped to carry out the experiments, data analysis, collection, and interpretation. Macêdo, RO, Souza, FS, supervised the development of work, helped in data interpretation and manuscript edition and evaluation, performed a critical revision of the article.

\section{CONFLICT OF INTERESTS}

The authors have not declared any conflict of interests

\section{REFERENCES}

1. Queiroz LP. Leguminosas da Caatinga. $1^{\text {st }}$ Ed. Feira de Santana (BA): Editora Universitária da UEFS; 2009.

2. Albuquerque UP, Medeiros PM, Almeida ALS, Monteiro JM, Lins Neto EMF, Melo JG, et al. Medicinal plants of the caatinga (semiarid) vegetation of NE Brazil: A quantitative approach. J Ethnopharmacol 2007;114 Suppl 3:325-54.

3. Cartaxo SL, Souza MMA, Albuquerque UP. Medicinal plants with bioprospecting potential used in semi-arid northeastern Brazil. J Ethnopharmacol 2010;131 Suppl 2:326-42.

4. Souza MZS, Andrade LRS, Fernandes MSM. Levantamento sobre plants medicinais comercializadas na feira livre da cidade de Esperança-PB. Biofar 2011;5 Suppl 1:111-8.

5. Bahia MV, David JP, David JM. The occurrence of by flavones in leaves of Caesalpinia pyramidalis specimens. Quim Nova 2010;33 Suppl 6:1297-300.

6. Bahia MV, Santos JB, David JP, David JM. Biflavonoids and other phenolics of Caesalpinia pyramidalis (Fabaceae). J Braz Chem Soc 2005;16 Suppl 6b:1402-5.

7. Melo JG, Araújo TAS, Castro VTNA, Cabral DLV, Rodrigues MD, Nascimento SC, et al. Antiproliferative activity, antioxidant 
capacity and tannin content in plants of semi-arid Northeastern Brazil. Molecules 2010;15 Suppl 12:8534-42.

8. Mendes CC, Bahia MV, David JM, David JP. Constituents of Caesalpinia pyramidalis. Fitoterapia 2000;71 Suppl 2:205-7.

9. Monteiro JM, Lins Neto EMF, Amorim ELC, Strattmann RR, Araújo EL, Albuquerque UP. Teor de taninos em três espécies medicinais arbóreas simpátricas da caatinga. Rev Arvore 2005;29 Suppl 6:999-1005.

10. Oliveira JCS. Estudo químico e avaliação biológica do extrato das cascas das raízes de Caesalpinia pyramidalis Tul. (Leguminosae). Dissertação de Mestrado. Universidade Federal da Bahia, Salvador; 2010.

11. Ribeiro AR, Diniz PF, Estevam CS, Pinheiro M, Albuquerque-Jr RLC, Thomazzi S. Gastroprotective activity of the ethanol extract from the inner bark of Caesalpinia pyramidalis in rats. J Ethnopharmacol 2013;147 Suppl 2:383-8.

12. Giulietti AM, Soares MBP, Santos RR. Atividade antibacteriana em alguns extratos de vegetais do semiárido brasileiro. Rev Bras Farmacogn 2003;13 Suppl 2:4-7.

13. Pereira Jr LR, Andrade AP, Araújo KD, Barbosa AS, Barbosa FM. Espécies da caatinga como alternativa para o desenvolvimento de novos fitofármacos. Floresta Ambient 2014;21 Suppl 4:509-20.

14. Santana DG, Santos CA, Santos ADS, Nogueira PCL, Thomazzi SM, Estevam CS, et al. Beneficial effects of the ethanol extract of Caesalpinia pyramidalis on the inflammatory response and abdominal hyperalgesia in rats with acute pancreatitis. J Ethnopharmacol 2012;142 Suppl 2:445-55.

15. Santos AC, Ailane MPR, Passos FCA, Camargo EA, Estevam CS, Santos MRV, et al. Antinociceptive and anti-inflammatory effects of Caesalpinia pyramidalis in rodents. Braz J Pharmacogn 2011;21:1077-83.

16. Santos CA. Estudo farmacológico do extra to etanólico da entrecasca da Caesalpinia pyramidalis Tul. (Leguminosae). Dissertação de Mestrado-Universidade Federal da Paraíba, Aracajú; 2010.

17. Souza CR, Shave to IA, Thomazini FCF, Oliveira WP. Processing of Rosmarinus officinalis Linne extracts on spray and spouted bed dryers. Braz J Chem Eng 2008;25:59-69.

18. Oliveira WP, Bott RF, Souza CRF. Manufacturer of standardized dried extracts from medicinal Brazilian plants. Drying Technol 2006;24:523-33.

19. Bott RF, Labuza TP, Oliveira WP. Stability testing of spray and spouted bed-dried extracts of Passiflora alata. Drying Technol 2010;28:1255-65.

20. Thirugnanasambandham K, Sivakumar V, Prakash JN. Optimization of electrocoagulation process to treat grey wastewater in batch mode using response surface methodology. J Environ Health Sci Eng 2014;12:29.

21. Sarala M, Velu V, Anandharamakrishnan C, Singh RP. Spray drying of Tinospora cordifolia leaf and stem extract and evaluation of antioxidant activity. J Food Sci Technol 2012;49:119-22.
22. Tonon RV, Brabet $\mathrm{C}$, Hubinger MD. Influence of process conditions on the physic-chemical properties of acai powder produced by spray drying. J Food Eng 2008;88:411-8.

23. Muzaffar K, Kumar P. Parameter optimization for spray drying of tamarind pulp using response surface methodology. Powder Tecnol 2015;279:179-84.

24. Patil V, Chauhan AK, Sing RP. Optimization of the spray-drying process for developing guava powder using response surface methodology. Powder Tecnol 2014;253:230-36.

25. Pradeep BV, Akilandeswari P, Usha RV, Palaniswamy M. Application of multifactorial experimental design for optimization of prodigiosin production using Serratia marcescens MBB01, MBB02, AND MBB05. Asian J Pharm Clin Res 2016;9:408-16.

26. Veit, M. Note for guidance on stability testing of existing herbal drug preparations and related herbal medicinal products. Pharm Indian 2002;64:20-3.

27. Leite RS, Souza VG, Oliveira AH, Júnior JVC, Salvador IS, Andrade FHD, et al. Standardization and stability evaluation of dry extracts of Myracrodruon urundeuva Allemão obtained by spray drier. Int J Pharm Pharm Sci 2017;9:154-9.

28. ICH Q2B. Department of Health and Human Services. Food and Drug Administration. Center for Drug Evaluation Research. Guidance for industry: ICH Q2B Validation of analytical procedures: methodology. Rockville; 1995.

29. Klu MW, Addy BS, Oppong EE, Sakyi ES, Mintah NM. Effect of storage conditions on the stability of ascorbic acid in some formulations. Int J Appl Pharm 2016;8:26-31.

30. Thirugnanasambandham K, Sivakumar V. Influence of process conditions on the physicochemical properties of pomegranate juice in spray drying process: Modelling and optimization. J Saudi Soc Agric Sci 2015.

31. Scibisz I, Kalisz S, Mitek M. Thermal degradation of anthocyanins in blueberry fruit. Zywn Nauk Technol Ja 2010;72:56-66.

32. Hiemori $\mathrm{M}$, Koh $\mathrm{E}$, Mitchell AE. Influence of cooking on anthocyanins in black rice (Oryza sativa L. japonica var. SBR). J Agric Food Chem 2009;57:1908-14.

33. Bott RF, Labuza TP, Oliveira WP. Stability testing of spray and spouted bed-dried extracts of Passiflora alata. Drying Technol 2010;28:1255-65.

\section{How to cite this article}

- Agna Hélia De Oliveira, Renata Da Silva Leite, Fabrício Havy Dantas, Valmir Gomes De Souza, José Venâncio Chaves Júnior, Fábio Santos De Souza, Rui Oliveira Macedo. Thermal degradation kinetics of kaempferol and quercetin in the preformulated of the standardized extracts of poincianella pyramidalis (TUL.) L. P. queiroz obtained by spray dryer. Int J Pharm Pharm Sci 2017;9(6):123-128. 